\title{
Are urothelial carcinomas of the upper urinary tract a distinct entity from urothelial carcinomas of the urinary bladder? Behavior of urothelial carcinoma after radical surgery with respect to anatomical location: a case control study
}

\author{
Myong Kim, Chang Wook Jeong, Cheol Kwak, Hyeon Hoe Kim and Ja Hyeon Ku*
}

\begin{abstract}
Background: To compare the prognosis of upper urinary tract (UUT)-urothelial carcinoma (UC) and UC of the bladder (UCB) by pathological staging in patients treated with radical surgeries.

Methods: The study population comprised 335 and 302 consecutive radical surgery cases performed between 1991 and 2010 for UUT-UC and UCB, respectively. Five-year recurrence-free survival (RFS) and cancer-specific survival (CSS) rates were analyzed. The median follow-up period of all subjects was 59.3 months (range, 0.1-261.0 months).

Results: No difference was observed in median patient age, distribution of pathologic $T$ stage, or rates of positive surgical margin between the two groups. The UUT-UC group had significantly more frequent hydronephrosis than the USB group ( $48.1 \%$ vs. $20.2 \%, p<0.001)$. However, the UUT-UC group showed significantly less frequent grade III tumors ( $28.1 \%$ vs. $58.6 \%, p<0.001)$, lymphovascular invasion ( $18.8 \%$ vs. $35.8 \%, p<0.001)$, and associated carcinoma in situ $(9.0 \%$ vs. $21.9 \%, p<0.001)$ than the UCB group. Five year RFS rates in the UUT-UC and UCB groups were $77.0 \%$ and $75.9 \%$, respectively $(p=0.546)$. No significant difference in RFS rate was observed between pathological T stage subgroups. Five year CSS rates in the UUT-UC and UCB groups were $76.1 \%$ and $76.2 \%$, respectively $(p=0.462)$. No significant difference was observed in CSS rate between the pathologic T stage subgroups.
\end{abstract}

Conclusions: UUT-UC and UCB showed comparable prognosis at identical stages. However, our results should be verified in a prospective study due to the retrospective study design in this study.

Keywords: Bladder cancer, Upper tract urothelial carcinoma, Radical cystectomy, Radical nephroureterectomy, Prognosis

\section{Background}

Urothelial carcinoma (UC) is the fourth most common tumor in the United States and Europe, representing a heterogeneous groups of cancers [1]. UC can be located in any urothelial epithelia of the entire urinary tract. UC of the bladder (UCB) is the most common type of $\mathrm{UC}$, accounting for $95 \%$. Upper urinary tract (UUT)-UC represents $5 \%$ of $\mathrm{UC}$ at the initial diagnosis [2]. A $30-51 \%$

\footnotetext{
* Correspondence: kuuro70@snu.ac.kr

Department of Urology, Seoul National University College of Medicine, 101 Daehak-ro, Jongno-gu, Seoul 110-744, Korea
}

risk of bladder recurrence within 5 years was reported for patients who underwent radical nephroureterectomy for UUT-UC [3], with a $2-6 \%$ risk of developing a subsequent UUT-UC after UCB [4].

The two types of UC share common pathogenic mechanisms. They are expected to show analogous tumor characteristics [5] with similar prognostic risk factors [6,7]. However, although pathological staging of the two types of tumors is based identically on the natural anatomy of the UUT and the bladder, there have been some concerns that UUT may be more vulnerable to tumor spreading compared to that of the urinary bladder. The thinner muscle 
layer structure [8] and abundant lymphatic and blood channels [9] of the UUT are postulated to make tumor invasion and metastasis easier than those in UCB. In fact, it was reported UUT-UC was more invasive and metastatic than that of UCB at initial diagnosis [10], with $60 \%$ of UUT-UC as invasive at diagnosis compared to only $15 \%$ of UCB. There is strong clinical, etiological, epidemiological, and genetic evidence that UUT-UC and UCB should be considered distinct urothelial entities [11].

Currently, it is not clear whether the prognoses of these two types of UC are different for identical pathological staging. Therefore, we designed this study to compare the prognosis of UUT-UC and UCB by staging patients treated with radical surgery.

\section{Methods}

\section{Patient selection}

This study protocol was approved by the institutional review board of Seoul National University Hospital, Seoul, South Korea. The study population comprised 760 consecutive radical surgery cases of UUT-UC or UCB performed between 1991 and 2010 at our institution (Figure 1). Of the 760 cases, 37 (9.7\%) of radical nephroureterectomy cases and 64 (17.0\%) of radical cystectomy cases were excluded from analysis. The reasons for exclusion are shown in Figure 1. Since there was a possibility of pathologic downstaging in patients who received neoadjuvant chemotherapy, we excluded 38 patients who received neoadjuvant. Thereafter, 11 (1.7\%) of the remaining cases were identified to receive concomitant radical nephroureterectomy and radical cystectomy.
Therefore, 335 patients with UUT-UC and 302 with UCB were analyzed in the current study.

\section{Treatments and follow-up}

The workup, surgery, pathological review, and followup have been described in details previously $[12,13]$. Lymph node dissection (LND) was conducted in selective cases in the UUT-UC group that were suspicious for metastatic nodes based on preoperative evaluation. The extent of LND was decided by the surgeon. Radical cystectomy with pelvic LND was routinely performed in cases of muscle invasive $\mathrm{UCB}(\mathrm{pT} \geq 2)$, pT1 with concurrent carcinoma in situ (CIS), recurrence after intravesical Bacille Calmette-Guérin (BCG) immunotherapy, or with variant histologic subtypes such as micropapillary form. The extent of pelvis LND was limited below the bifurcation of common iliac vessels in most patients. A few patients underwent LND above the iliac bifurcation.

Excised specimens were processed according to standard pathological procedures. Tumor-node-metastasis staging of the tumor was classified by the 6th revised recommendation of the American Joint Cancer Committee 2002 [14]. Tumor grade was assessed based on the 1973 World Health Organization classification. Tumor recurrence was defined as local failure at the operative site, regional LNs, or distant metastasis at follow-up evaluations. Lymphovascular invasion (LVI) was defined as positive tumor cells in the vessel-like endothelium-lined space without the muscular wall. Cause of death was determined by the clinician based on chart review and authorized death certificate.

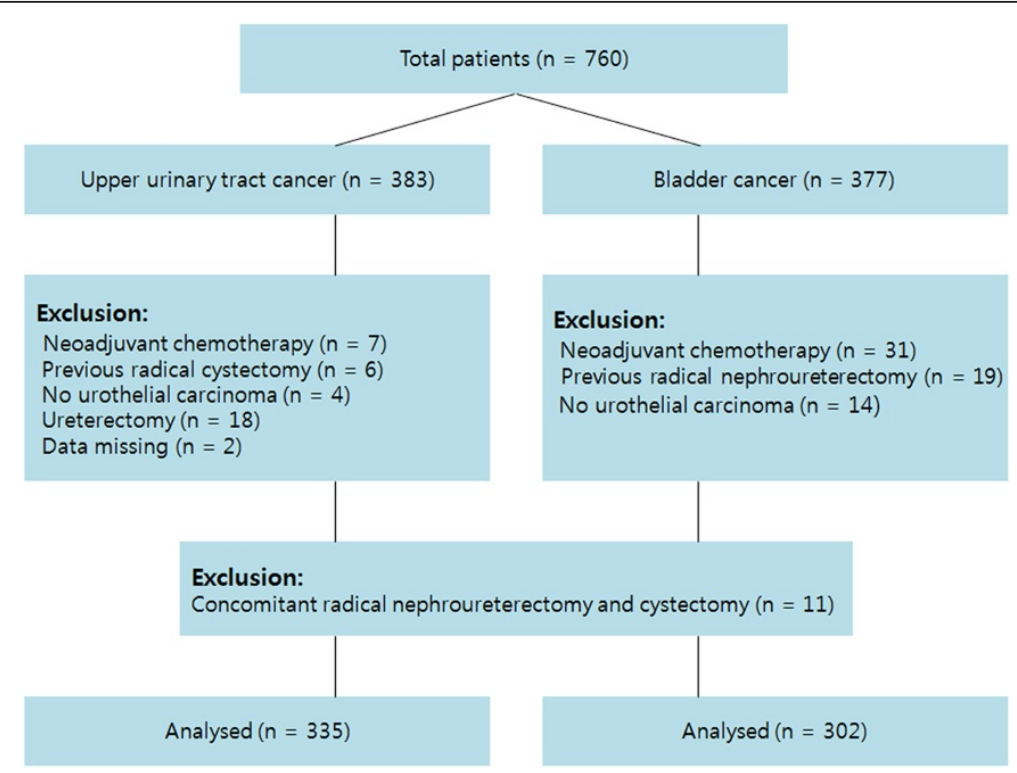

Figure 1 Patient selection. 
Perioperative deaths occurring within 30 days of surgery were censored.

\section{Statistical analyses}

Five-year recurrence-free survival (RFS) and cancerspecific survival (CSS) rates were analyzed. KaplanMeier curve and log-rank analyses were applied to compare survival in the two groups. The prognostic factors assessed were: tumor location (UUT vs. bladder), age, sex, body mass index (BMI), American Society of Anesthesiologists (ASA) score, presence of hydronephrosis, pathological $\mathrm{T}$ stage, pathological $\mathrm{N}$ stage, tumor grade, LVI or associated CIS, and margin status. All significant variables in the univariate analysis were included in a multivariate Cox model. Statistical analysis was performed using SPSS (SPSS Inc., Chicago, IL, USA). All tests were two-tailed with a significance level considered when $\mathrm{p}$ value was less than 0.05 .

\section{Results}

The descriptive characteristics of the 335 UUT-UC and 302 UCB patients are summarized in Table 1. The median follow-up for all subjects was 59.3 months (range, $0.1-261.0$ months). Of the 302 UCB patients, 36 (10.5\%) had no residual tumor (pT0). No difference in median age or pathologic $\mathrm{T}$ stage distribution was observed between the two groups. The two types of tumors were male dominant $(79.1 \%$ vs. $89.4 \%, \mathrm{p}<0.001)$. The UUTUC group had significantly higher BMI (24.2 vs. 23.4, $\mathrm{p}=0.001)$, higher ASA score $\geq 2(66.0 \%$ vs. $55.0 \%$, $\mathrm{p}=0.005)$, and more frequent hydronephrosis $(48.1 \% \mathrm{vs}$. $20.2 \%, \mathrm{p}<0.001)$ than the UCB group. However, the UUT-UC group showed less frequent grade III tumors $(28.1 \%$ vs. $58.6 \%, \mathrm{p}<0.001)$, LVI $(18.8 \%$ vs. $35.8 \%$, $\mathrm{p}<0.001)$, and associated CIS ( $9.0 \%$ vs. $21.9 \%, \mathrm{p}<0.001)$ than the UCB group. There was no difference in the rate of positive surgical margins between the two groups ( $4.2 \%$ vs. $7.6 \%, \mathrm{p}=0.064)$.

The Kaplan-Meier curves for RFS of the two groups stratified into three pathologic $\mathrm{T}$ stage subgroups are shown in Figure 2. Five year RFS rates of the UUT-UC and UCB groups were $77.0 \%$ and $75.9 \%$, respectively $(\mathrm{p}=0.546)$ (Figure 2A). No significant difference in RFS rate was observed among pathologic $\mathrm{T}$ stage subgroups (Figure 2B-D).

Univariate and multivariate analyses to predict RFS in all patients after radical surgery are summarized in Table 2. In the univariate analysis, BMI, presence of hydronephrosis, pathological $\mathrm{T}$ stage, pathological $\mathrm{N}$ stage, tumor grade, LVI, and positive surgical margin were highly significant predictors of recurrence. In the multivariate analysis including those parameters, pathological T stage (pT2, hazard ratio [HR]: 2.88, 95\% confidence interval $[\mathrm{CI}]: 1.57-5.26, \mathrm{p}=0.001 ; \geq \mathrm{pT} 3, \mathrm{HR}$ :
Table 1 Patient characteristics

\begin{tabular}{|c|c|c|c|c|c|}
\hline & \multicolumn{2}{|c|}{$\begin{array}{l}\text { Upper urinary } \\
\text { tract cancer }\end{array}$} & \multicolumn{2}{|c|}{ Bladder cancer } & \multirow[t]{2}{*}{$P$ value } \\
\hline & $\begin{array}{l}\text { No. of } \\
\text { patients }\end{array}$ & $\%$ & $\begin{array}{l}\text { No. of } \\
\text { patients }\end{array}$ & $\%$ & \\
\hline No. of patients & 335 & 100 & 302 & 100 & \\
\hline Age, years & & & & & 0.217 \\
\hline Mean & 63.0 & & 62.0 & & \\
\hline Range & $29.5-90.0$ & & $21.0-85.6$ & & \\
\hline Sex & & & & & $<0.001$ \\
\hline Male & 265 & 79.1 & 270 & 89.4 & \\
\hline Female & 70 & 20.9 & 32 & 10.6 & \\
\hline Body mass index, $\mathrm{kg} / \mathrm{m}^{2}$ & & & & & 0.001 \\
\hline Mean & 24.2 & & 23.4 & & \\
\hline Range & $13.8-38.8$ & & $13.9-32.5$ & & \\
\hline ASA score & & & & & 0.005 \\
\hline 1 & 114 & 34.0 & 136 & 45.0 & \\
\hline$\geq 2$ & 221 & 66.0 & 166 & 55.0 & \\
\hline Hydronephrosis & 161 & 48.1 & 61 & 20.2 & $<0.001$ \\
\hline Pathological T category & & & & & 0.584 \\
\hline$\leq \mathrm{pT} 1$ & 131 & 39.1 & 113 & 37.4 & \\
\hline pT2 & 58 & 17.3 & 62 & 20.5 & \\
\hline$\geq \mathrm{pT3}$ & 146 & 43.6 & 127 & 42.1 & \\
\hline Pathological N category & & & & & $<0.001$ \\
\hline $\mathrm{pN-}$ & 39 & 11.6 & 237 & 78.5 & \\
\hline $\mathrm{pN+}$ & 16 & 4.8 & 65 & 21.5 & \\
\hline $\mathrm{pNx}$ & 280 & 83.6 & 0 & 0.0 & \\
\hline Tumor grade & & & & & $<0.001$ \\
\hline$\leq \|$ & 241 & 71.9 & 125 & 41.4 & \\
\hline III & 94 & 28.1 & 177 & 58.6 & \\
\hline LVI & 63 & 18.8 & 108 & 35.8 & $<0.001$ \\
\hline Associated CIS & 30 & 9.0 & 66 & 21.9 & $<0.001$ \\
\hline Positive surgical margin & 14 & 4.2 & 23 & 7.6 & 0.064 \\
\hline
\end{tabular}

Abbreviations: ASA = American Society of Anesthesiologists, LVI = Lymphovascular invasion, CIS = carcinoma in situ.

4.68, 95\% CI: 2.74-7.99, $\mathrm{p}<0.001)$, pathological N stage (HR: $1.85,95 \%$ CI: $1.18-2.89, \mathrm{p}=0.007$ ), and LVI (HR: 1.50, 95\% CI: $1.04-2.15, \mathrm{p}=0.029)$ remained independent predictors of recurrence. However, tumor location (UUT vs. bladder) did not affect RFS.

Five year CSS rates of the UUT-UC and BCB groups were $76.1 \%$ and $76.2 \%$, respectively $(p=0.462)$ (Figure 3A). No significant difference in CSS rate was observed among pathologic $\mathrm{T}$ stage subgroups (Figure 3B-D).

Cox models used to predict CSS are shown in Table 3. In the univariate analysis, age, BMI, hydronephrosis, pathological $\mathrm{T}$ and $\mathrm{N}$ stage, tumor grade, LVI, and positive surgical margin were significant predictors of cancer-specific 


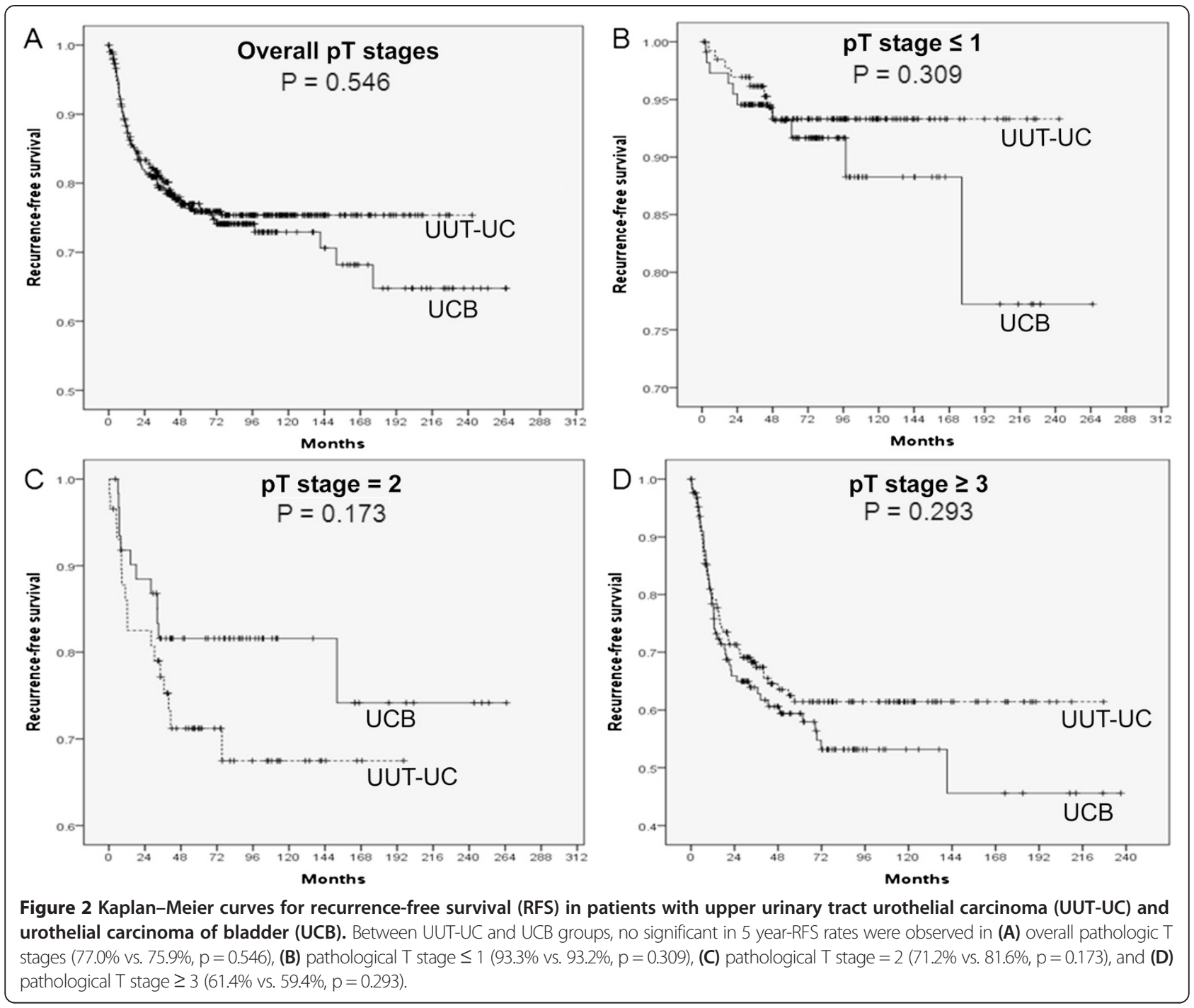

death. In the multivariate analysis, age (HR: 1.03, 95\% CI: 1.01-1.044, $\mathrm{p}=0.002$ ), hydronephrosis (HR: $1.41,95 \% \mathrm{CI}$ : 1.02-1.96, $\mathrm{p}=0.041$ ), pathological T stage (pT2, HR: 2.71, 95\% CI: $1.50-4.88, \mathrm{p}=0.001$; $\geq$ pT3, HR: $4.96,95 \%$ CI: 2.94-8.36, p < 0.001), pathological N stage ( $\mathrm{pN}, \mathrm{HR}$ : 1.99 , 95\% CI: $1.28-3.07, \mathrm{p}=0.002$ ), and LVI (HR: $1.66,95 \% \mathrm{CI}$ : $1.16-2.37, \mathrm{p}=0.005)$ were independent predictors. Tumor location was not a predictor of CSS.

\section{Discussion}

UC can develop in a synchronous or metachronous multifocal manner at different urinary tract sites. Due to the relative preponderance of $\mathrm{UCB}$, much of the clinical decision making regarding UUT-UC is extrapolated from evidence gained on UCB. However, because UUT-UC is biologically unique with appreciable genetic, molecular, and clinical differences from UDB [15], it remains questionable whether UCB findings could be safely extrapolated to UUT-UC.
Patients with UUT-UC generally have more advanced disease at the initial diagnosis $[10,16]$. Stewart et al. reported that tumor grade $\geq 3(44 \%$ vs. $35 \%, \mathrm{p}=0.003)$ and pathologic $\mathrm{T}$ stage $\geq 2(33 \%$ vs. $20 \%, \mathrm{p}=0.001)$ were more frequent in UUT-UC than those in UCB [16]. Several hypotheses have been proposed for the different tumor behavior of UUT-UC compared to UCB. Thinner muscle layer structure [8] and abundant lymphatic and blood channels [9] of UUT have been postulated to make tumor invasion or metastasis easier in patients with UUT-UC. These anatomical features of UUT representing thinner muscle/adventitia layer and smaller caliber lumen, can cause hardship to ensure sufficient healthy tissue for a safe surgical margin following conservative UUT-UC surgery [17]. Therefore, technical limitations of UUT-UC sampling compared to transurethral resection for bladder tumors may be the most important cause of staging differences between UUT-UC and UCB. Aside from these anatomical characteristics 
Table 2 Univariate and multivariate Cox proportional hazard regression analyses of recurrence-free survival

\begin{tabular}{|c|c|c|c|c|}
\hline & \multicolumn{2}{|l|}{ Univariate } & \multicolumn{2}{|l|}{ Multivariate } \\
\hline & $\mathrm{HR}(95 \% \mathrm{Cl})$ & $P$ value & $\mathrm{HR}(95 \% \mathrm{Cl})$ & $P$ value \\
\hline \multicolumn{5}{|l|}{ Tumor location } \\
\hline Upper urinary tract vs. Bladder & $0.906(0.658-1.248)$ & 0.546 & & \\
\hline Age, years & 1.016 (0.999-1.033) & 0.057 & & \\
\hline \multicolumn{5}{|l|}{ Sex } \\
\hline Female vs. Male & $1.098(0.719-1.676)$ & 0.665 & & \\
\hline Body mass index, kg/m2 & 0.947 (0.898-0.999) & 0.049 & $0.980(0.929-1.033)$ & 0.453 \\
\hline \multicolumn{5}{|l|}{ ASA score } \\
\hline$\geq 2$ vs.1 & $0.927(0.670-1.282)$ & 0.645 & & \\
\hline \multicolumn{5}{|l|}{ Hydronephrosis } \\
\hline Present vs. Absent & $1.609(1.165-2.221)$ & 0.004 & 1.378 (0.984-1.928) & 0.062 \\
\hline \multicolumn{5}{|l|}{ Pathological T category } \\
\hline pT2 vs. $\leq$ pT1 & $3.588(1.992-6.461)$ & $<0.001$ & $2.875(1.573-5.256)$ & 0.001 \\
\hline$\geq \mathrm{pT} 3$ vs. $\leq \mathrm{pT} 1$ & $6.748(4.087-11.141)$ & $<0.001$ & 4.675 (2.736-7.990) & $<0.001$ \\
\hline \multicolumn{5}{|l|}{ Pathological N category } \\
\hline pNx vs. pN- & $1.174(0.810-1.700)$ & 0.397 & $1.202(0.805-1.794)$ & 0.369 \\
\hline $\mathrm{pN}+$ vs. pN- & $3.232(2.113-4.942)$ & $<0.001$ & $1.847(1.180-2.889)$ & 0.007 \\
\hline \multicolumn{5}{|l|}{ Tumor grade } \\
\hline III vs. $\leq \|$ & $1.955(1.416-2.699)$ & $<0.001$ & $1.151(0.802-1.652)$ & 0.447 \\
\hline \multicolumn{5}{|l|}{ LVI } \\
\hline Present vs. Absent & $2.639(1.911-3.645)$ & $<0.001$ & $1.496(1.042-2.149)$ & 0.029 \\
\hline \multicolumn{5}{|l|}{ Associated CIS } \\
\hline Present vs. Absent & $1.054(0.681-1.631)$ & 0.815 & & \\
\hline \multicolumn{5}{|l|}{ Surgical margin } \\
\hline Positive vs. Negative & $2.777(1.675-4.605)$ & $<0.001$ & $1.349(0.797-2.282)$ & 0.265 \\
\hline
\end{tabular}

$[8,9]$, some differences in the molecular biology of UUT have also been suggested as etiology of different tumor behavior [18-21]. Hartmann et al. reported that microsatellite instability (MSI) present in UTT-UC was correlated with mutation of human DNA mismatch repair genes and clinicopathological characteristic of tumor [18]. Roupret et al. also demonstrated that MSI was rarely encountered in UCB (approximately 3\%), whereas it occurred in more than 15\% of sporadic UTT-UC [19]. Catto et al. reported that the frequency of UUT-UC appeared to be significantly higher than UCB (94\% vs. $76 \%$ ) which might be associated with the poorer clinicopathologic outcomes of UUT-UC [20]. Single-nucleotide polymorphisms (SNP) variability of rs9642880[T] allele on 8q24 and rs798766[T] allele on 4p16 was not associated with disease aggressiveness of UCB. However, they were associated with more aggressive tumors when stratified by stage for UTT-UC [21]. These characteristics seem to make tumor invasion and metastasis easier in patients with UUT-UC [22]. Thus, radical nephroureterectomy with excision of the bladder cuff is recommended as the initial treatment of choice for high-grade UUT-UC.

However, it is still unclear whether the more aggressive behavior of UUT-UC have originated from different innate tumor biology or advanced status of the tumor at diagnosis. Some investigators have hypothesized that if the aggressiveness of UUT-UC is due to an initial higher stage, the prognosis may not be different between UUTUC and UCB after stratification by stages. Catto et al. reported that 150 UUT-UC cases and 275 UCB cases showed similar prognoses (cancer-specific death, 35\% vs. 43\%) [17]. However, the population used in that study had a different distribution of pathological $\mathrm{T}$ stage ( $\geq$ pT2, 35\% vs. 62\%). Moreover, non-muscle invasive $\mathrm{UCB}$ cases received transurethral resection of bladder tumors, whereas all patients with UUT-UC underwent radical nephroureterectomy. Although the authors selected a subgroup of UCB patients with balanced pathological status to compare the prognosis between UUT-UC and UCB, the selection criteria were not described clearly. In addition, the selected cases were only 


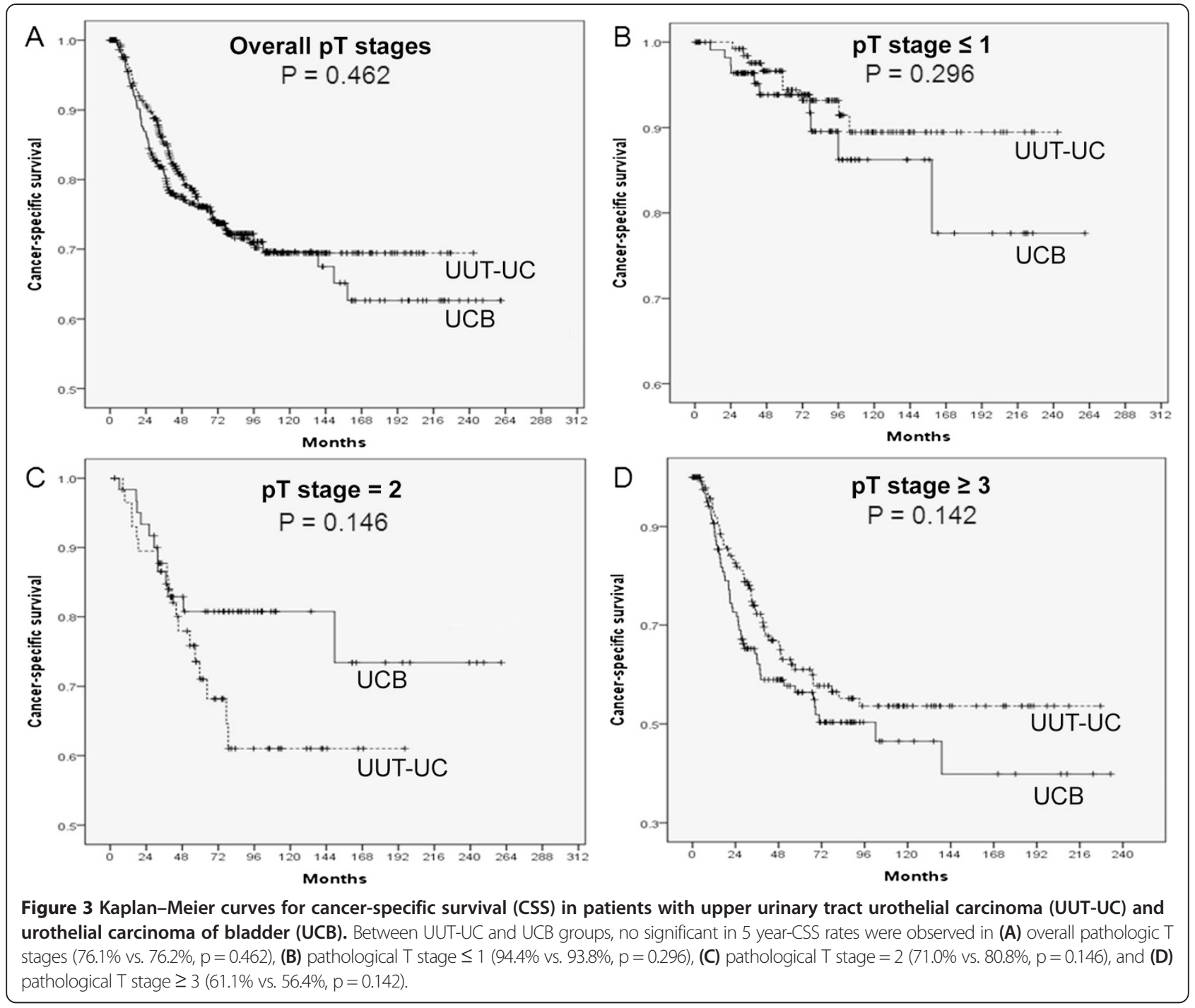

from one institution of four participating centers. Therefore, there may have been selection bias. Moussa et al. [23] also found no difference in overall survival after controlling for the effects of tumor stage. In contrast to the study of Catto et al. [17], Moussa et al. [23] compared only patients who underwent radical surgery. They reported that patients with UCB have more advanced pathology than those of UUT-UC cohort.

In a recent multicenter study of 4,335 patients with UCB and 877 patients with UUT-UC, all patients were treated with radical surgery. It was found that stage and grade were independent predictors of CSS for the overall cohort [24]. However, in stage-specific analyses of patients with pT1 or less and pT4 disease, UCB and UUT-UC were independently predictive for CSS. They explained that the inferior outcomes of non-muscle invasive UCB patients as follows, "Non-muscle invasive $U C B$ patients undergo radical cystectomy because of features of aggressive biopsy. The lack of appropriate staging and grading, poor selection leads to high rates of radical nephroureterectomy for UUT-UC. Delay in diagnosis and/or treatment may differentially affect outcomes in these patients".

Our results are in consistent with those of previous studies $[17,23]$. Our subjects were comprised only of patients who received radical surgery for UUT-UC or UCB. As a result, our two groups showed similar pathological $\mathrm{T}$ stage characteristics $(\mathrm{p}=0.584)$ (Table 1). Our data also revealed that UUT-UC and bladder cancer had identical 5-year RFS and CSS rates after radical surgery in all pathological $\mathrm{T}$ stage stratified subgroups (Figure 2 and Figure 3).

Our study had several limitations. This study was limited by the retrospective nature of the analysis with a relatively small number of patients. In addition, all patients with UCB underwent concomitant pelvic LND, whereas the UUT-UC cases underwent LND in only selective cases (55 of 280, 16.4\%). Evidence of LND during 
Table 3 Univariate and multivariate Cox proportional hazard regression analyses of cancer-specific survival

\begin{tabular}{|c|c|c|c|c|}
\hline & \multicolumn{2}{|l|}{ Univariate } & \multicolumn{2}{|l|}{ Multivariate } \\
\hline & $\mathrm{HR}(95 \% \mathrm{Cl})$ & $P$ value & $\mathrm{HR}(95 \% \mathrm{Cl})$ & $P$ value \\
\hline \multicolumn{5}{|l|}{ Tumor location } \\
\hline Upper urinary tract vs. Bladder & $0.889(0.650-1.216)$ & 0.462 & & \\
\hline Age, years & $1.022(1.005-1.039)$ & 0.010 & $1.027(1.010-1.044)$ & 0.002 \\
\hline \multicolumn{5}{|l|}{ Sex } \\
\hline Female vs. Male & $0.980(0.643-1.493)$ & 0.926 & & \\
\hline Body mass index, kg/m2 & $0.921(0.874-0.971)$ & 0.002 & $0.965(0.916-1.016)$ & 0.177 \\
\hline \multicolumn{5}{|l|}{ ASA score } \\
\hline$\geq 2$ vs.1 & $0.978(0.711-1.343)$ & 0.889 & & \\
\hline \multicolumn{5}{|l|}{ Hydronephrosis } \\
\hline Present vs. Absent & $1.672(1.221-2.289)$ & 0.001 & $1.409(1.015-1.957)$ & 0.041 \\
\hline \multicolumn{5}{|l|}{ Pathological T category } \\
\hline pT2 vs. $\leq$ pT1 & 3.410 (1.919-6.058) & $<0.001$ & $2.707(1.500-4.884)$ & 0.001 \\
\hline$\geq$ pT3 vs. $\leq$ pT1 & $7.115(4.366-11.593)$ & $<0.001$ & $4.960(2.943-8.359)$ & $<0.001$ \\
\hline \multicolumn{5}{|l|}{ Pathological N category } \\
\hline pNx vs. pN- & $1.126(0.784-1.619)$ & 0.520 & $1.126(0.760-1.669)$ & 0.554 \\
\hline $\mathrm{pN}+$ vs. pN- & $3.580(2.364-5.422)$ & $<0.001$ & $1.986(1.282-3.074)$ & 0.002 \\
\hline \multicolumn{5}{|l|}{ Tumor grade } \\
\hline III vs. $\leq \|$ & $1.963(1.432-2.689)$ & $<0.001$ & $1.105(0.778-1.567)$ & 0.578 \\
\hline \multicolumn{5}{|l|}{ LVI } \\
\hline Present vs. Absent & 2.875 (2.098-3.938) & $<0.001$ & $1.663(1.164-2.374)$ & 0.005 \\
\hline \multicolumn{5}{|l|}{ Associated CIS } \\
\hline Present vs. Absent & $0.971(0.624-1.512)$ & 0.898 & & \\
\hline \multicolumn{5}{|l|}{ Surgical margin } \\
\hline Positive vs. Negative & 3.158 (1.930-5.166) & $<0.001$ & $1.483(0.888-2.477)$ & 0.132 \\
\hline
\end{tabular}

radical nephroureterectomy is important for prognosis [25]. The low rate of LND in patients with UUT-UC might lead to an undefined bias regarding clinical outcomes. However, pelvic LND at the time of radical cystectomy is widely accepted, whereas LND at the time of radical nephroureterectomy is performed largely at the discretion of the surgeon, which may be due, in part, to the variable lymphatic drainage along the course of the ureter compared to the relatively confined lymphatic landing sites for the bladder [26]. Our results demonstrated that $\mathrm{pNx}$ was not an independent prognostic factor for RFS ( $p=0.369)$ or CSS ( $p=0.554$ ) when compared to pN0 (Tables 2 and 3). Moreover, patients who received neoadjuvant chemotherapy were excluded from this study because the proportion of patients who received neoadjuvant chemotherapy was decisively different between the two groups. Because of the high resemblance of UUT-UC to UCB, neoadjuvant chemotherapy for UUT-UC is expected to produce similar results to those seen in UCB. However, one unique challenge for UUT-UC when incorporating neoadjuvant chemotherapy into therapy regimens is the associated limitation to clinical staging [27]. Since limited prospective data existed for neoadjuvant chemotherapy in UUT-UC, these data are currently insufficient to provide any recommendations. Recommended policies on neoadjuvant chemotherapy in UUT-UC and UCB are different [28-30]. Finally, there may have been dissimilarities in management between patients with UUT-UC and UCB in our cohort. Patients with pT1 or less UCB were generally treated with transurethral resection of the bladder tumor with or without intravesical therapy, whereas all patients with high-grade UUT-UC were recommended to undergo radical nephroureterectomy due to the inability to accurately stage and resect the tumor and/or effectively deliver intracavitary therapy [26].

\section{Conclusions}

UUT-UC and UCB showed comparable prognosis at identical stages. However, due to the retrospective study design, our results should be verified in a prospective study. 


\section{Abbreviations}

UUT: Upper urinary tract; UC: Urothelial carcinoma; UCB: Urothelial carcinoma of the bladder; RFS: Recurrence-free survival; CSS: Cancer-specific survival; LND: Lymph node dissection; LVI: Lymphovascular invasion; BMI: Body mass index; ASA: AMERICAN Society of Anesthesiologists; CIS: Carcinoma in situ.

\section{Competing interests}

The authors declare that they have no competing interests.

\section{Authors' contributions}

MK participated in the statistical analysis and drafted the manuscript. CWJ carried out the acquisition of data helped to draft the manuscript. CK participated in revising the manuscript critically for important intellectual content. HHK participated in the design of the study and in revising the manuscript critically. JHK participated in the design of the study and performed the statistical analysis. All authors read and approved the final manuscript.

\section{Authors' information}

Myong Kim is the first author.

Received: 29 March 2014 Accepted: 5 March 2015

Published online: 18 March 2015

\section{References}

1. Ploeg M, Aben $\mathrm{KH}$, Kiemeney $\mathrm{L}$. The present and future burden of urinary bladder cancer in the world. World J Urol. 2009:27:289-93.

2. Siegel R, Naishadham D, Jemal A. Cancer statistics, 2012. CA Cancer J Clin. 2012:62:10-29.

3. Azémar MD, Comperat E, Richard F, Cussenot O, Rouprêt M. Bladder recurrence after surgery for upper urinary tract urothelial cell carcinoma: frequency, risk factors, and surveillance. Urol Oncol. 2011;29:130-6.

4. Sanderson KM, Rouprêt M. Upper urinary tract tumour after radical cystectomy for transitional cell carcinoma of the bladder: an update on the risk factors, surveillance regimens and treatments. BJU Int. 2007:100:11-6.

5. Canfield SE, Dinney CP, Droller MJ. Surveillance and management of recurrence for upper tract transitional cell carcinoma. Urol Clin North Am. 2003:30:791-802

6. Novara G, De Marco V, Gottardo F, Dalpiaz O, Bouygues V, Galfano A, et al. Independent predictors of cancer-specific survival in transitional cell carcinoma of the upper urinary tract. Cancer. 2007;1 10:1715-22.

7. Sylvester RJ, van der Meijden APM, Oosterlinck W, Witjes JA, Bouffioux C, Denis $L$, et al. Predicting recurrence and progression in individual patients with stage Ta T1 bladder cancer using EORTC risk tables: a combined analysis of 2596 patients from seven EORTC trials. Eur Urol. 2006;49:466-77.

8. van der Poel HG, Antonini $\mathrm{N}$, van Tinteren $\mathrm{H}$, Horenblas S. Upper urinary tract cancer: location is correlated with prognosis. Eur Urol. 2005;48:438-44.

9. Park J, Ha SH, Min GE, Song C, Hong B, Hong JH, et al. The protective role of renal parenchyma as a barrier to local tumor spread of upper tract transitional cell carcinoma and its impact on patient survival. J Urol. 2009;182:894-9.

10. Kondo T, Nakazawa H, Ito F, Hashimoto $Y$, Toma H, Tanabe K. Primary site and incidence of lymph node metastases in urothelial carcinoma of upper urinary tract. Urology. 2007;69:265-9.

11. Yates DR, Catto JW. Distinct patterns and behaviour of urothelial carcinoma with respect to anatomical location: how molecular biomarkers can augment clinico-pathological predictors in upper urinary tract tumours. World J Urol. 2013;31:21-9.

12. $\mathrm{Ku} \mathrm{JH}$, Moon $\mathrm{KC}$, Jung $\mathrm{JH}$, Jeong $\mathrm{SH}$, Kwak C, Kim HH. External validation of an online nomogram in patients undergoing radical nephroureterectomy for upper urinary tract urothelial carcinoma. Br J Cancer. 2013;109:1130-6.

13. Moon KC, Kim M, Kwak C, Kim HH, Ku JH. External validation of online predictive models for prediction of cancer-specific mortality and all-cause mortality in patients with urothelial carcinoma of the urinary bladder. Ann Surg Oncol 2014, doi:10.1245/s10434-014-3561-5.

14. Sobin LH, Wittekind C. TNM classification of malignant tumours. York: Wiley-Liss; 2002.

15. Kauffman EC, Raman JD. Bladder cancer following upper tract urothelial carcinoma. Expert Rev Anticancer Ther. 2008:8:75-85
16. Stewart GD, Bariol SV, Grigor KM, Tolley DA, McNeill SA. A comparison of the pathology of transitional cell carcinoma of the bladder and upper urinary tract. BJU Int. 2005;95:791-3.

17. Catto JWF, Yates DR, Rehman I, Azzouzi AR, Patterson J, Sibony M, et al. Behavior of urothelial carcinoma with respect to anatomical location. J Urol. 2007:177:1715-20.

18. Hartmann A, Zanardo L, Bocker-Edmonston T, Blaszyk H, Dietmaier W, Stoehr $\mathrm{R}$, et al. Frequent microsatellite instability in sporadic tumors of the upper urinary tract. Cancer Res. 2002;62:6796-802.

19. Rouprêt M, Azzouzi AR, Cussenot O. Microsatellite instability and transitional cell carcinoma of the upper urinary tract. BJU Int. 2005;96:489-92.

20. Catto JWF, Azzouzi A-R, Rehman I, Feeley KM, Cross SS, Amira N, et al. Promoter hypermethylation is associated with tumor location, stage, and subsequent progression in transitional cell carcinoma. J Clin Onco. 2005:23:2903-10

21. Yates DR, Rouprêt M, Drouin SJ, Audouin M, Cancel-Tassin G, Comperat E, et al. Genetic polymorphisms on 8q24.1 and 4p16.3 are not linked with urothelial carcinoma of the bladder in contrast to their association with aggressive upper urinary tract tumours. World J Urol. 2013;31:53-9.

22. Favaretto RL, Shariat SF, Chade DC, Godoy G, Adamy A, Kaag M, et al. The effect of tumor location on prognosis in patients treated with radical nephroureterectomy at Memorial Sloan-Kettering Cancer Center. Eur Urol. 2010;58:574-80.

23. Moussa S, Yafi FA, El-Hakim A, Fahmy N, Aprikian A, Tanguay S, et al. Outcome of surgical treatment of patients with upper versus lower urinary tract urothelial carcinoma: stage-by-stage comparison. Urol Int. 2010;84:50-5.

24. Rink M, Ehdaie B, Cha EK, Green DA, Karakiewicz PI, Babjuk M, et al. Stage-specific impact of tumor location on oncologic outcomes in patients with upper and lower tract urothelial carcinoma following radical surgery. Eur Urol. 2012;62:677-84.

25. Roscigno M, Cozzarini C, Bertini R, Scattoni V, Freschi M, Da Pozzo LF, et al. Prognostic value of lymph node dissection in patients with muscle-invasive transitional cell carcinoma of the upper urinary tract. Eur Urol. 2008:53:794-802.

26. Green DA, Rink M, Xylinas E, Matin SF, Stenzl A, Roupret M, et al. Urothelial carcinoma of the bladder and the upper tract: disparate twins. J Urol. 2013;189:1214-21

27. Alva AS, Matin SF, Lerner SP, Siefker-Radtke AO. Perioperative chemotherapy for upper tract urothelial cancer. Nat Rev Urol. 2012;9:266-73.

28. Clark PE, Agarwal N, Biagioli MC, Eisenberger MA, Greenberg RE, Herr HW, et al. Bladder cancer. J Natl Compr Canc Netw. 2013;11:446-75.

29. Stenzl A, Cowan NC, De Santis M, Kuczyk MA, Merseburger AS, Ribal MJ, et al. Treatment of muscle-invasive and metastatic bladder cancer: update of the EAU guidelines. Eur Urol. 2011;59:1009-18.

30. Rouprêt M, Zigeuner R, Palou J, Boehle A, Kaasinen E, Sylvester R, et al. European guidelines for the diagnosis and management of upper urinary tract urothelial cell carcinomas: 2011 update. Eur Urol. 2011;59:584-94.

\section{Submit your next manuscript to BioMed Central and take full advantage of:}

- Convenient online submission

- Thorough peer review

- No space constraints or color figure charges

- Immediate publication on acceptance

- Inclusion in PubMed, CAS, Scopus and Google Scholar

- Research which is freely available for redistribution 